\title{
The Concept of a Pedolateral Pes Revisited: The Giant Sloths Megatherium and Eremotherium (Xenarthra, Folivora, Megatheriinae) as a Case Study
}

\author{
Néstor Toledo $^{1,2}$ (iD $\cdot$ Gerardo De Iuliis ${ }^{3,4} \cdot$ Sergio F. Vizcaíno ${ }^{1,2} \cdot$ M. Susana Bargo ${ }^{1,5}$
}

Published online: 6 September 2017

(C) Springer Science+Business Media, LLC 2017

\begin{abstract}
The concept of a pedolateral pes in many extinct sloths began effectively with Owen's mid-nineteenth century descriptions of Glossotherium and Megatherium. Pedolaterality denotes a pes that is habitually inverted, with the digital plane oriented nearly vertically so that weight is borne largely by the lateral digits (mainly metatarsal V) and the plantar surface faces almost entirely medially. Subsequent researchers were strongly influenced by Owen's interpretations. Astragalar morphology, with the medial and lateral portions of its trochlea forming, respectively, a peg-shaped odontoid process and a discoid facet, came to be viewed as a proxy for pedolaterality and, eventually, horizontal rotation around a nearly vertical axis as the main movement of the
\end{abstract}

Néstor Toledo

ntoledo@fcnym.unlp.edu.ar

Gerardo De Iuliis

gerry.deiuliis@utoronto.ca

Sergio F. Vizcaíno

vizcaino@fcnym.unlp.edu.ar

M. Susana Bargo

msbargo@fcnym.unlp.edu.ar

1 División Paleontología Vertebrados, Unidades de Investigación, Anexo Museo, Facultad de Ciencias Naturales y Museo, Av. 60 y 122, 1900 La Plata, Buenos Aires, Argentina

2 Consejo Nacional de Investigaciones Científicas y Técnicas (CONICET), Buenos Aires, Argentina

3 Department of Ecology and Evolutionary Biology, University of Toronto, 25 Harbord Street, Toronto, Ontario M5S 3G5, Canada

4 Department of Palaeobiology, Royal Ontario Museum, 100 Queen's Park Circle, Toronto, Ontario M5S 2C6, Canada

5 Comisión de Investigaciones Científicas de la Provincia de Buenos Aires (CIC), La Plata, Buenos Aires, Argentina pes. Such motion necessitates a nearly vertical orientation for the odontoid process. However, analysis of the pes of the Pleistocene megatheriines Megatherium and Eremotherium, the astragalus of which conforms to the type usually interpreted in the literature as indicative of pedolaterality, suggests that the pes was not strongly inverted. Rather, the digital plane was about $35^{\circ}$ to the horizontal plane, so that weight was borne largely by metatarsal V, but also by metatarsal IV and possibly the ungual phalanx of digit III. The astragalus was positioned so that the odontoid process was oriented obliquely to the vertical axis. With this element so positioned, mediolateral rotation in the horizontal plane was minor, and the main movement of the pes produced dorsiflexion and plantar flexion in nearly the parasagittal plane, the usual movement of the pes in terrestrial mammals.

Keywords Xenarthra $\cdot$ Folivora $\cdot$ extinct sloth $\cdot$ foot anatomy $\cdot$ foot inversion

\section{Introduction}

Sloths (Folivora), together with anteaters (Vermilingua), and armadillos (including glyptodonts) and pampatheres (Cingulata), form Xenarthra, one of the most prominent and conspicuous clades of South and Central American placental mammals. The present diversity of sloths comprises only two genera of medium-sized, suspensory forms (two-toed sloths Choloepus and three-toed sloths Bradypus: see Mendel 1985; Reid 1997; Chiarello 2008; Nyakatura et al. 2010) that are distantly related (Patterson and Pascual 1968; Webb 1985; Gaudin 2004). However, their fossil record reveals a considerable diversity including more than 90 genera documented since the early Oligocene (see McDonald and De Iuliis 2008; Pujos et al. 2012 for a review). Extinct sloths included 
medium-sized climbing forms (White 1993, 1997; Bargo et al. 2012; Toledo et al. 2014; Toledo 2016) to fully terrestrial giants (Casinos 1996; de Toledo 1996; Fariña et al. 1998; Blanco and Czerwogonora 2003; De Esteban-Trivigno et al. 2008), forms able to dig (Zárate et al. 1998; Bargo et al. 2000; Vizcaíno et al. 2001), and even semiaquatic taxa (Muizon et al. 2004; Amson et al. 2014, 2015a, b). Most accepted phylogenetic hypotheses (Fig. 1) recognize five main sloth clades (Gaudin 1995, 2004; Pujos et al. 2012; Amson et al. 2016): Bradypus (Bradypodidae), a lineage with no known fossil record; Megalonychidae (Choloepus and a diversity of extinct forms ranging from small- to large-sized taxa); Nothrotheriidae (comprising a diversity of medium- to largesized forms); Megatheriidae (including medium-sized forms to giants such as the Pleistocene Eremotherium and Megatherium); and Mylodontidae (large to giant forms, such as Scelidotherium, Glossotherium - well suited for diggingParamylodon, Mylodon, and the gigantic Lestodon).

One of the most intriguing features of the pes of extant and most extinct sloths is the nature of the inward torsion of its elements (see McDonald 1977, 2003, 2007, 2012; Hirschfeld 1985; Webb 1989; McDonald and De Iuliis 2008; Argot 2008; see also Amson and Nyakatura 2017 this special issue). As well, many of their tarsals are considerably different morphologically from those of most mammals, and no modern analogies with any other mammal have been proposed (De Iuliis 1996). In extant sloths, inward rotation of the pes (so that the plantar surface faces medially) has been described in relation to their slow-climbing, arboreal habits (see Mendel 1985). In most extinct sloths such rotation resulted in a configuration in which weight was supported mainly by the calcaneum and fifth metatarsal (Mt V) (McDonald 2012), with the remaining digits having little or no support function. Termed "pedolateral" by most authors (see McDonald 1977, 2003, 2007, 2012; Hirschfeld 1985; Webb 1989; Amson et al. 2015a) and "invertigrade" by de Toledo (1996), this condition appears to evolve in a complex way, given that the lineages exhibit different degrees of pes modification, and that the most well-known assemblage among older sloths, the early Miocene Santacrucian forms of Patagonia (see White 1993, 1997; Bargo et al. 2012; Toledo 2016), which include many mid-sized members of most sloths lineages, possess a generalized, conservative pes without marked digit reduction (Toledo et al. 2015a, b; Fig. 2). However, one of the earliest taxa exhibiting the derived astragalar morphology is Octodontotherium from the late Oligocene (Deseadan) of Patagonia, which McDonald (2007) considered the earliest record of pedolaterality. Hirschfeld (1985) argued that features related to the pedolateral condition are traceable to anteaters, but McDonald $(2007,2012)$ claimed that pedolaterality was not derived from a common ancestor and that different sloth lineages apparently acquired the condition independently.

The concept of pedolaterality may be traced to Owen's 1842 description of Glossotherium, for which he stated that the pes, when articulated with the crus, rested on the substrate by its outer or lateral margin, and that the discoid facet (lateral crest of the astragalar trochlea) was almost horizontal and hence orthogonal to the odontoid facet (medial crest of the astragalar trochlea; Fig. 3). In his monograph on Megatherium americanum, Owen (1859) described the astragalus as assuming a similar orientation as in Glossotherium and that, similarly, a

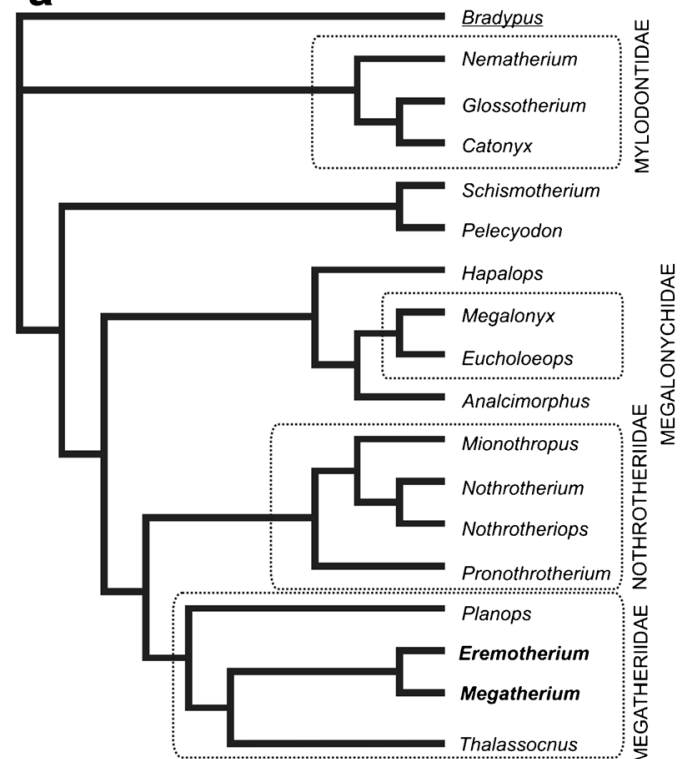

b

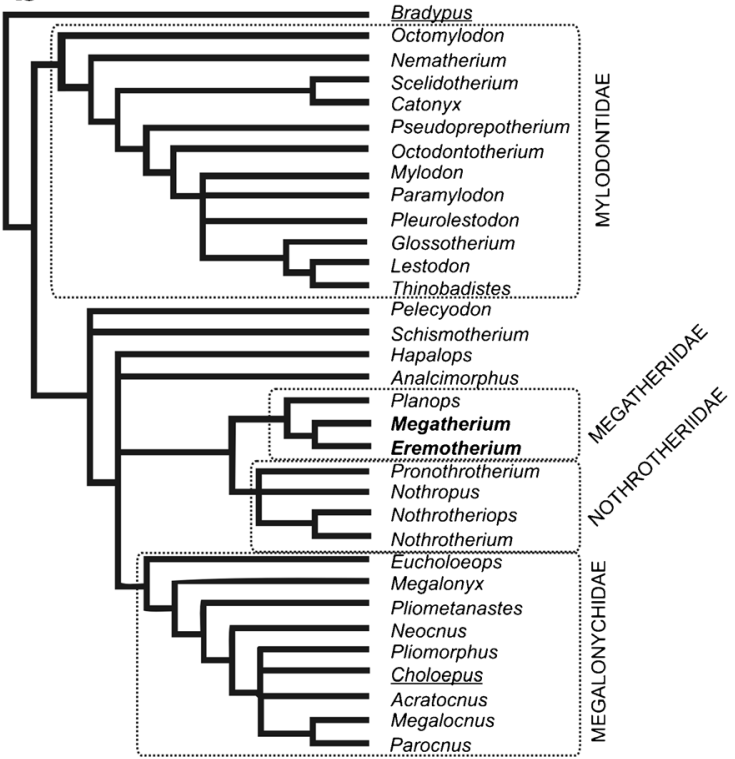

Fig. 1 Phylogenetic relationships of Folivora as depicted following hypotheses provided by a, Amson et al. (2016), and b, Gaudin (2004). Megatheriines analyzed in this work are in bold. Extant sloths are underlined 
a

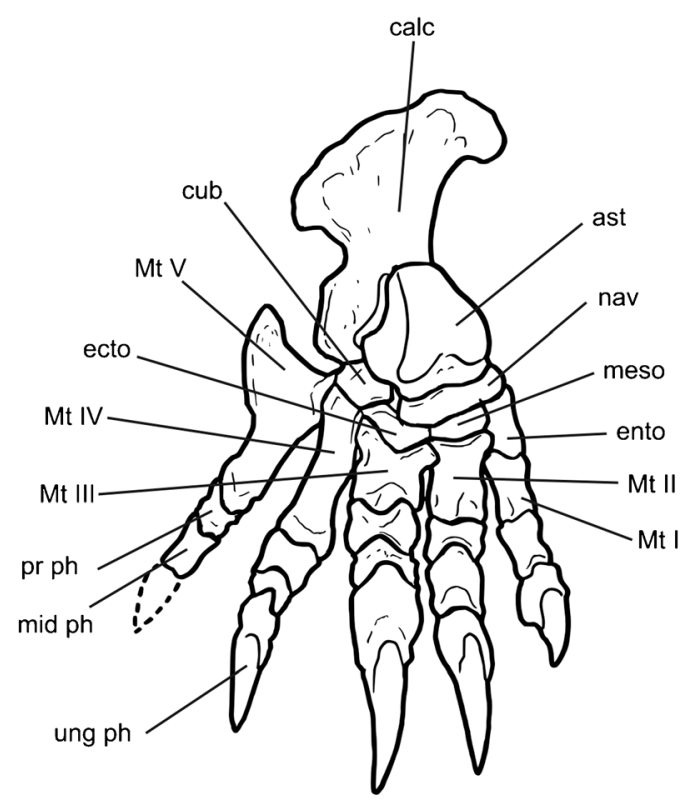

Fig. 2 Comparative anatomy in dorsal view of right pes of a, Hapalops (an early Miocene Santacrucian sloth; see Toledo et al. 2015a, b) and of b, Megatherium (based on MLP 2-73), showing the conservative morphology of the Santacrucian form as opposed to the highly modified arrangement of the Pleistocene genus. Abbreviations as follows: ast, astragalus; calc, calcaneum; cub, cuboid; ecto, ectocuneiform; ento, entocuneiform; fmid-pr ph, fused

the tibia articulated with the side of the astragalus and that the pes rested on its outer surface. De Iuliis (1996) proposed that Owen's interpretation was incorrect and suggested that Owen may have been influenced by the orientation of the fibular facet, which Owen (1859) described as facing dorsally if the astragalus were oriented with the pes in a plantigrade position. Owen further proposed that the odontoid process, oriented nearly vertically, played the role of a kind of pivot for movement of the pes, and illustrated the pes with the astragalar odontoid process directed almost entirely vertically. Owen's ideas and illustrations strongly influenced later researchers, and the presence of a well-developed odontoid process has generally been a proxy for inferring a pes orientation with plantar surface facing medially and weight borne largely or entirely by the lateral surface of the pes, influencing the depiction of most extinct sloths as large, slow herbivores (de Toledo 1996). Although Owen did not suggest that rotational pivoting in the horizontal plane (i.e., mediolateral rotation) around the odontoid process was the main movement in the pes of Megatherium (see De Iuliis 1996) rather than dorsiflexion and plantar flexion, these ideas were presented, expanded, and applied to other groups of extinct sloths by, for example,

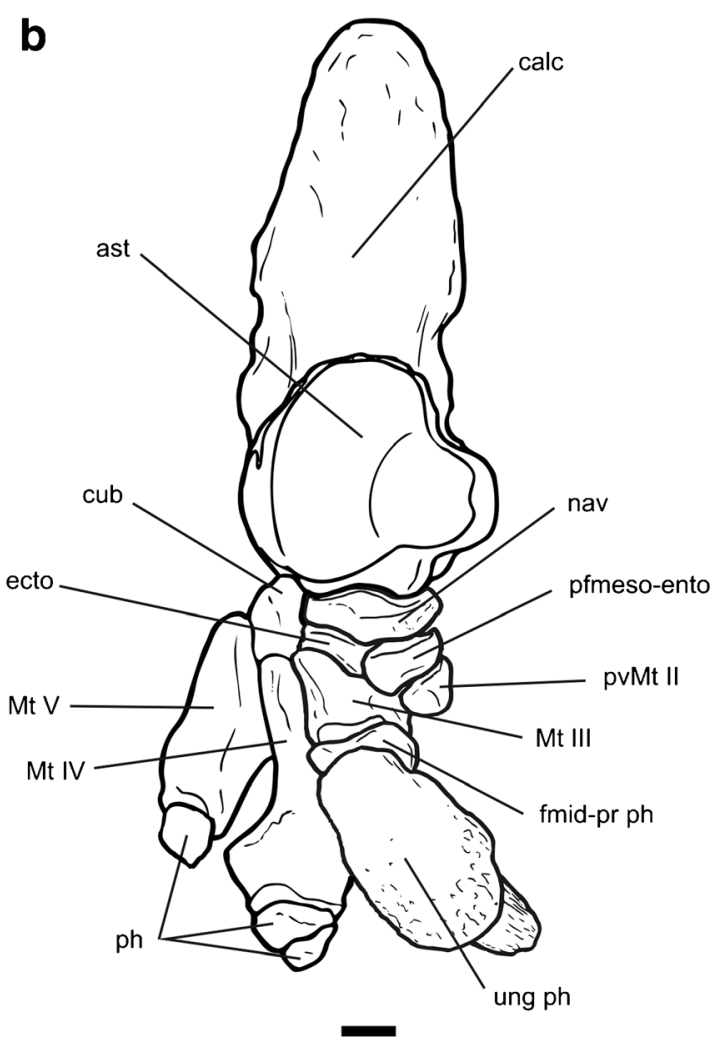

middle and proximal phalanges; meso, mesocuneiform; mid ph, middle phalanx; Mt I, first metatarsal; Mt II, second metatarsal; Mt III, third metatarsal; Mt IV, fourth metatarsal; Mt V, fifth metatarsal; nav, navicular; pfmeso-ento, probable fused mesoentocuneiform; ph, vestigial phalanges; pr ph, proximal phalanx; pvMt II, probable vestigial second metatarsal; ung ph, ungual phalanx. Scale bar $=5 \mathrm{~cm}$

Stock (1917, 1925), Hirschfeld (1985), McDonald (2003, 2007, 2012), and Amson et al. (2015a).

Thus, inversion of the pes has been correlated with modification of the ankle joint from an astragalus with a generalized mammalian configuration (see Polly 2007) towards a highly derived odontoid-discoid morphology, and a change in movement at the cruroastragalar joint from mainly dorsiflexion and plantar flexion to mainly or entirely mediolateral rotation. Once postulated, the pedolateral pes has also then, in turn, been used to interpret other anatomical functions or features: for example, Amson et al. (2015a) related pedolaterality to knee abduction and hence linked to femoral condylar asymmetry and patellar groove asymmetry, among other features (see below).

Perhaps the clearest expression of the link between a welldeveloped odontoid process (that is, with the process and the odontoid facet that it bears meeting the discoid facet at an angle of nearly $90^{\circ}$ ) and pedolaterality is provided by McDonald (2012: 211):

"In the megalonychids, the angle between the medial and lateral trochlea is close to $0^{\circ}$ [altered to $180^{\circ}$ by, 
Fig. 3 Megatheriinae right astragalus (a-e; Eremotherium laurillardi, ROM 22068) and tibia-fibula (f; Eremotherium laurillardi, USNM 457115). a, anterior view (proximal or tibial side towards top; lateral or fibular side towards left); $\mathbf{b}$, dorsal (tibial or proximal) view (anterior towards bottom, lateral towards left); c, medial view (plantar towards bottom, anterior towards left); d, lateral (fibular) view (proximal towards top, anterior towards right); e, dorsolateral view commonly and mistakenly depicted as lateral, with odontoid process oriented nearly vertically; f, distal (astragalar) view of right tibiafibula (anterior towards top, lateral towards left) showing cochlea tibiae. Abbreviations: aff, astragalar facet of fibula; cub, cuboidal facet of astragalus; dis, discoid facet; dit, discoid groove of cochlea tibiae; efa, ectal facet of astragalus; ffa, fibular facet of astragalus; nav, navicular facet of astragalus; odo, odontoid facet on odontoid process; odt, odontoid facet of cochlea tibiae; sus, sustentacular facet of astragalus. Scale bar $=5 \mathrm{~cm}$ a

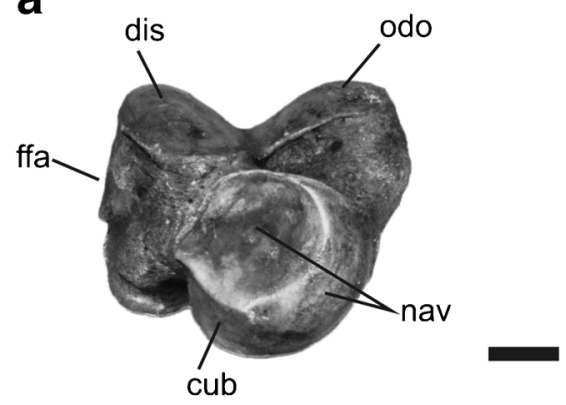

b

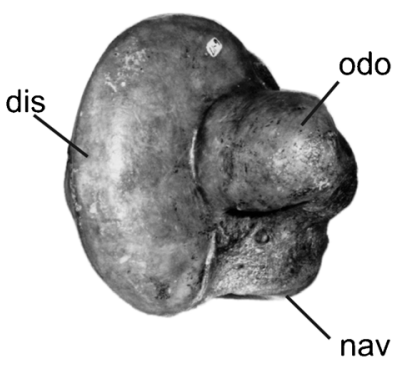

C

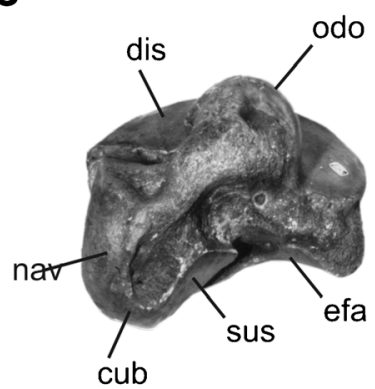

d

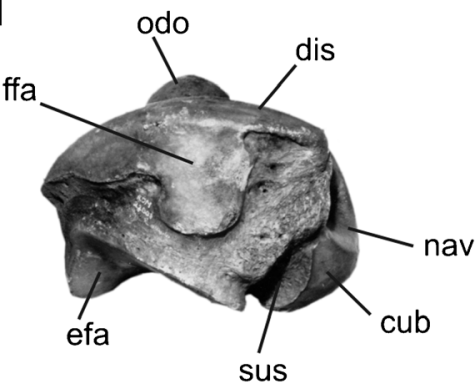

f

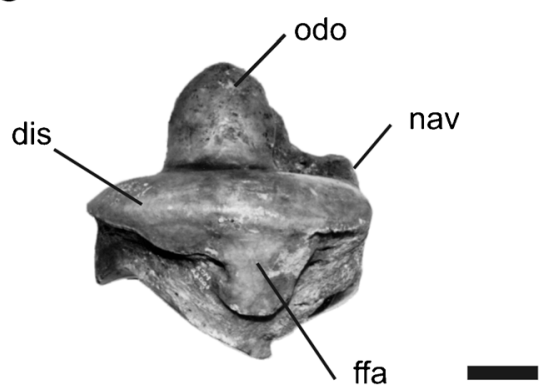

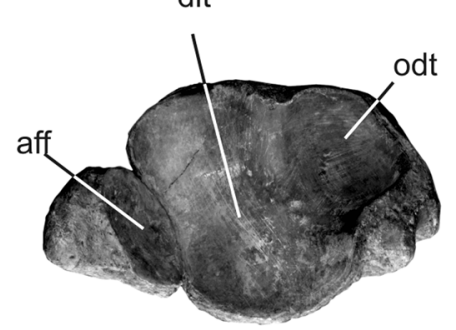

for example, Amson et al. (2015a)] while in the most derived taxa such as the mylodontids, Lestodon . . . and Paramylodon ... or megatheres such as Megatherium and Eremotherium . . . , the angle between the medial and lateral trochlea approaches $90^{\circ}$. The angle between the two trochleae in other sloths such as the nothrotheres (e.g., Nothrotheriops, . . .) and scelidotheriines (e.g., Catonyx, ...) will vary between these two extremes. If one considers the extremes in the angle between the two trochlear surfaces resulting from the modification of the medial trochlea, a totally unmodified astragalus with an angle of $0^{\circ}$ between the two trochleae has $100 \%$ dorsoplantar flexion and $0 \%$ mediolateral rotation, while an astragalus with a $90^{\circ}$ angle between the two trochleae has $0 \%$ dorsoplantar movement and $100 \%$ mediolateral rotation. Consequently, there is a direct relationship that with each degree increase in the angle between the medial and lateral trochlea, there is a concurrent loss of dorso-plantar movement with an equivalent gain in mediolateral rotation by the same amount. Therefore, in some clades, including some nothrotheres and scelidotheriines, with an angle between the medial and lateral trochlea that is intermediate between these two extremes, there will be a similar intermediate range of movement of the pes relative to the tibia, consisting of both a dorso-plantar extension-flexion as well as some mediolateral rotation."

Intermediate degrees of pedolaterality and dorsiflexionplantar flexion versus mediolateral rotation of the pes have been suggested (see e.g., McDonald 2012; Amson et al. 2015a, 2016) for sloths in which the odontoid process is not as well developed (that is, the angle between odontoid and discoid facets is between $0^{\circ}$ (or $180^{\circ}$ ) and $90^{\circ}$. However, our observations on some sloths (see below) suggest that this generally accepted view (that is, as expressed by McDonald) is not accurate. 
This contribution considers the criteria for recognizing a pedolateral pes posture, including the movement at the cruroastragalar joint (ankle joint), in terms of the morphology and architectural pattern of the pes as well as functional morphology of the ankle joint in the Pleistocene megatheriines Megatherium and Eremotherium, one member of which, as noted above, was among the first examples cited as possessing a pedolateral pes. Such analysis provides insight on the correlation between anatomy, posture and function of the pes in these giant extinct sloths, and tests the traditionally accepted concepts of pedolaterality.

The questions that require comprehensive consideration and that are specifically addressed in this contribution are:

1) Does the presence of a well-developed odontoid process necessarily indicate full pedolaterality (i.e., in which the plantar surface of the pes faces nearly or entirely medially)?

2) Does the presence of a well-developed odontoid process necessarily indicate that the astragalus moved, at the cruroastragalar joint, mainly or entirely mediolaterally (i.e., rotated) in the horizontal or frontal plane to the complete or near exclusion of the typical dorsiflexion and plantar flexion movements in a nearly parasagittal plane of generalized terrestrial mammals at this joint?

\section{Material and Methods}

\section{Institutions}

American Museum of Natural History, New York, USA (AMNH); Field Museum of Natural History, Chicago, USA (FMNH); Museo Argentino de Ciencias Naturales "Bernardino Rivadavia," Ciudad Autónoma de Buenos Aires, Argentina (MACN); Museo de La Plata, La Plata, Argentina (MLP); Royal Ontario Museum, Toronto, Canada (ROM); Smithsonian Institution - United States National Museum, Washington, D.C., USA (USNM); Yale Peabody Museum, Vertebrate Paleontology Princeton University, New Haven, USA (YPM-VPPU).

\section{Materials}

Megatherium americanum: FMNH P13662, MACN-PV 54, MACN-PV 12815aa, MACN-PV 514, MLP 2-29, MLP 230, MLP 2-31, MLP 2-207, MLP 2-73, MLP 27-VII-1-1, MLP 44-XII-28-1, MLP 71-II-18-1, ROM 10439.

Eremotherium sp.: AMNH 55725, FMNH 207869; E. laurillardi: FMNH P26970, ROM 21928, ROM 21932 , ROM 21941, ROM 21953, ROM 21965, ROM 22008, ROM 22068, ROM 221973, ROM 23003, ROM 28856 ,
ROM 28860, ROM 28861, ROM 28863, ROM 28905, ROM 30768; USNM 457115.

Prepotherium potens: MACN-A 4694, YPM-VPPU 15345, YPM-VPPU 15521, YPM-VPPU 15568, YPMVPPU 15568.

Several Megatherium and Eremotherium specimens were studied in order to assess the reliability of the correlation between pes morphology and posture. For comparative purposes, specimens of the early Miocene megatheriid from Patagonia, Prepotherium, were included. To study function of the ankle joint, specimens with both astragalus and tibiafibula were articulated to gain insight on the angle and range of mobility at the cruroastragalar joint. When present, other pes elements (e.g., calcaneum, navicular, cuboid, cuneiforms, metatarsals, and phalanges) were articulated as well to analyze correlation between pedal architecture and posture.

\section{Anatomical terminology and orientation of limb elements}

In this work we will follow the anatomical reference framework from De Iuliis and Pulerá (2010). To avoid misconceptions, "digit" is considered as involving the metapodials and fingers, which are in turn composed by phalanges (see De Iuliis and Pulerá 2010), and hence "digital plane" is used to denote the plane defined by the array formed by metatarsals and phalanges, independent of the loss or fusion of elements. Concerning spatial orientation of pes elements, we considered here a generalized plantigrade mammalian pes as the anatomical reference frame for orientation (see Polly 2007). Thus, the following standard anatomical orientations are used in figures: anterior, posterior, dorsal, ventral (effectively plantar), medial, and lateral. The surface of the astragalus articulating with the distal surface of the tibia is considered part of its proximal surface. The distal surface of the astragalus is the surface, facing anteriorly, with which the more distal tarsals articulate. The surface that is toward the substrate is the plantar (or ventral) surface. Thus, a figure depicting the tibia and astragalus articulated in a life orientation and observed from the front of the animal is considered an anterior view, even though the distal surface of the astragalus is depicted. The surface of the tarsals, metatarsals, and phalanges that faces dorsally is considered the dorsal surface of these elements.

The following assumptions are made regarding hind limb posture in sloths:

1. The femur was approximately vertical, aligned with the parasagittal plane, as in most mammals (see Polly 2007).

2. The tibia and fibula were approximately vertical, aligned with the parasagittal plane, as in most mammals (see Polly 2007).

3. Some degree of knee abduction was considered, but preliminary observations of the knee joint anatomy suggest that the tibia was not strongly deviated from the 
parasagittal plane. Although femoral condylar asymmetry has been proposed as an indicator of knee abduction for extinct sloths (see Amson et al. 2015a, and indirectly as indicative of pedolaterality), it is important to note that knee abduction (with the femur and tibia in articulation and forming an angle in the transverse plane with the knee facing anteriorly; i.e., equivalent to the pathological condition genu varum in humans) is not the same as lateral excursion of the knee. The latter implies that the entire hind limb deviates laterally from a parasagittal plane due to mediolateral rotation at the femoroacetabular joint, with the knee directed anterolaterally, a position exhibited to varying degrees in many mammals (see Jenkins 1971: Fig. 4). A larger medial femoral condyle is observed in ground-dwelling extant xenarthrans (see White 1993; Toledo et al. 2015a, b), while fully arboreal ones exhibit subequal femoral condyles, in spite of frequently displaying lateral excursion of the knee. This is also described for extant marsupials by Argot (2002) and for extant rodents by Candela and Picasso (2008). In addition, Milne et al. (2012) proposed that body size has a strong effect on femoral morphology, with the largest xenarthrans (terrestrial sloths and glyptodonts) exhibiting more strongly asymmetrical femoral condyles, and indicating a stance with a more extended knee posture. Finally, many terrestrial mammals exhibit asymmetric femoral condyles and asymmetric patellar trochlear ridges without exhibiting knee abduction or pedolaterality at all (e.g., armadillos, carnivorans, pangolins, artiodactyls, perissodactyls, and
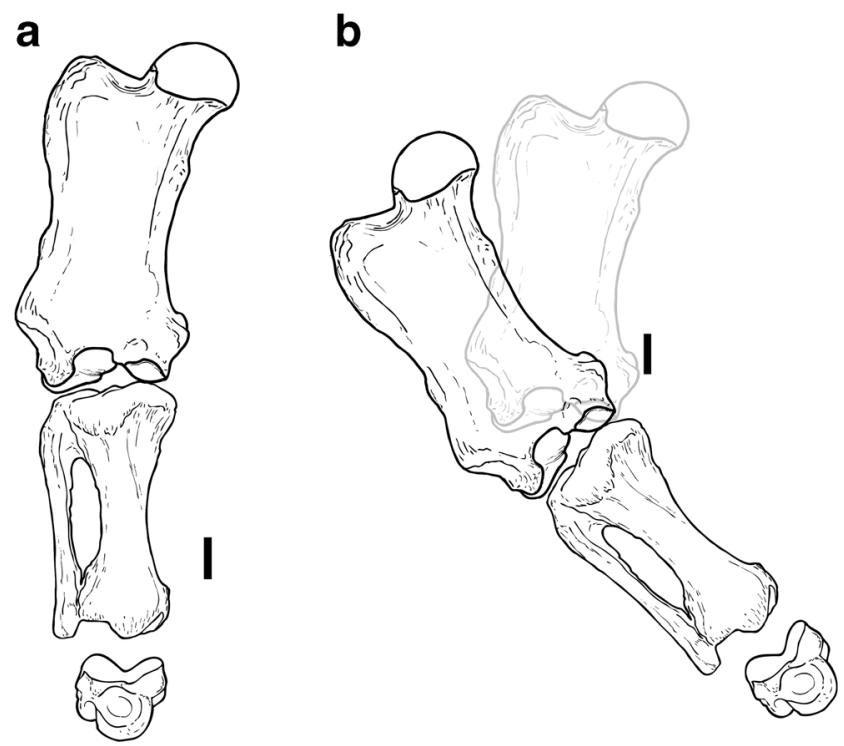

Fig. 4 Right femur, tibia-fibula and astragalus, in disarticulation, to reveal the orientation of the astragalus of megatheriines analyzed in this work: a, orientation followed in this work, with the tibia-fibula and femur approximately vertical and hence a non-inverted astragalus; $\mathbf{b}$, orientation of the tibia-fibula and femur required if astragalus is inverted as suggested by previous literature so that the odontoid process is oriented nearly vertically. Scale bar $=5 \mathrm{~cm}$ elephants, among others; pers. obs., but, see also examples in Lessertisseur and Saban 1971). Indeed, such features are readily observable in Equus, in which there is no question of pedolaterality. Femoral condylar asymmetry induces, also, a differential sliding of the tibial plateau, promoting axial rotation of the crus around its proximodistal axis during knee flexion and extension (see Lovejoy 2007; Milne et al. 2012), although functional interpretations of this feature are still in discussion. In summary, despite isolated efforts to understand features of the knee related with posture and locomotion in extinct sloths (compare discussions of Amson et al. 2015a and Toledo et al. 2015a, b), the subject requires further research.

Here, we do not consider any inference or assumption about putative upright posture and locomotion in extinct sloths (see for example Blanco and Czerwogonora 2003). The results of this contribution are not considered with respect to bipedal vs. quadrupedal posture and locomotion in extinct sloths.

\section{Results}

\section{Overall anatomy of pes}

In Eremotherium and Megatherium, the pes exhibits a highly derived arrangement with respect to the condition observed in early Miocene Santacrucian sloths and other stem megatheriids (see Toledo et al. 2015a, b; Amson et al. 2016). The astragalus bears distinct odontoid (medial trochlear crest) and discoid (lateral trochlear crest) facets that meet at a right angle in anterior view (Fig. 3a). The sessile astragalar head bears anteriorly the concave and convex facet for the navicular, with the concave portion approximately centered with the midline of the astragalar trochlea, and the convex portion more nearly plantar to the odontoid process. Plantarly, the head bears a convex facet for the cuboid (Fig. 3). In contrast to the Miocene genus Prepotherium and to other Pliocene megatheriines such as Pliomegatherium (Brandoni 2006) and Pyramiodontherium (Brandoni et al. 2004) where the angle between the fibular facet and astragalar trochlea is slightly acute (less than $90^{\circ}$ ), the angle between the fibular facet and the astragalar trochlea is slightly obtuse (more than $90^{\circ}$ ), as in the Miocene Megathericulus (De Iuliis et al. 2008). The calcaneum of both Megatherium and Eremotherium is elongated and wide, but its tuber narrows posteriorly (at its proximal end, following the terminology used by Amson et al. 2015a); it appears to have rested on the substrate along its entire length. The ectal facet, the main articular surface for the astragalus, is convex along its major axis, which is oriented obliquely from mediodorsal to 
lateroplantar. The sustentacular facet is similarly oriented, as in other extinct sloths, and contiguous lateroplantarly with that for the cuboid. The ectocuneiform is strongly anteroposteriorly (or proximodistally) compressed. The entoand mesocuneiform are usually fused into a single complex. Digits I and II are almost entirely absent in both genera (a reduced Mt II is observed in some specimens). Digit III is the only complete digit of the pes with fused proximal and middle phalanges and a large ungual phalanx bearing a curved ungual core. The lateral metatarsals are large but the corresponding phalanges are only vestigial (Fig. 2).

\section{Orientation of the cruroastragalar joint}

Orientation of the mediolateral major axis of the astragalar facets of both the tibia (cochlea tibiae or tibial cochlea) and fibula (forming together the astragalar mortise) is slightly oblique (about $12^{\circ}$ in Megatherium americanum, MACNPV 54) relative to the major axis of the tibial plateau in both Megatherium and Eremotherium. The concave median ridge of the cochlea tibiae, separating the astragalar facets, is oriented slightly posteromedially to anterolaterally. Thus, the axis of the medial surface of the cochlea tibiae, articulating with the odontoid facet of the astragalus (and thus the odontoid process itself), is tilted slightly anteriorly with respect to the transverse plane of the tibia (Fig. 3f). This implies that the astragalus (and hence the proximodistal axis of the pes as a whole) was oriented slightly laterally with respect to the vertical (or parasagittal) plane of the tibia.

Regarding tilting of the ankle in the transverse plane, when the astragalus is articulated with the tibia-fibula (usually fused), the cruroastragalar joint axis does not exhibit a marked vertical inclination (i.e., it is only slightly oblique to the frontal plane) unless the tibia is strikingly abducted at the knee joint (i.e., genu varum) and the anatomical evidence of both the tibia-fibula and femur support our reconstruction - that is, the tibia could only have undergone slight abduction at its proximal end without dislocation of the knee joint (Fig. 4). The medial and lateral facets of the cochlea tibiae do not exhibit marked differences in depth (e.g., MACN-PV 54, MLP 71-II-18-1, USNM 457115), indicating that the cochlea tibiae did not deviate markedly from the plane of the tibial plateau. In turn, this indicates that the astragalar trochlea was not markedly inclined either, similar to the early Miocene Santacrucian megatheriid Prepotherium potens (YPM-VPPU 15345 and 15568), and in contrast to Owen's (1859) depiction that was supported in later literature (Kraglievich 1928; Gazin 1957; Paula Couto 1978; Hirschfeld 1985; McDonald 2007, 2012). The distal facet of the fibula, converse to the condition observed in P. potens (see Toledo et al. 2015a, b), is oblique to the fibular diaphyseal axis (Fig. 4). In effect, then, when in anatomical position within the astragalar mortise, the astragalus was tilted no more than a few degrees, so that the most proximal part of the odontoid process of the astragalus projected proximally just slightly beyond the most lateral surface of the discoid facet (Fig. 4a).

\section{Inclination of the digital plane}

In Megatherium and Eremotherium, when the astragalus is in the anatomical position above defined, the navicular facet does not lie entirely dorsal to the cuboidal facet: the medial portion of the former lies approximately medial to the latter. This is because the long axis of the navicular facet is oriented dorsolaterally to plantomedially at approximately $35^{\circ}$ to the horizontal axis (or frontal plane). This orientation, in turn, establishes the orientation of the long axis of the ectocuneiform, so that the distal articular surface of the latter, for Mt III, is similarly inclined. The long axis of Mt III is thus likewise inclined so its keeled distal surface is also oblique, rather than dorsoplantarly aligned. This orientation is carried through the fused phalanges proximal to the large ungual phalanx of the third digit. The bony ungual core and it keratinous sheath in life were therefore directed plantomedially.

Mt IV articulated laterally with Mt V, dorsomedially with Mt III, and proximally with cuboid, and Mt III articulated proximally with the entocuneiform. The spatial arrangement of these articulations were such that the plane of the digital array at the cuboid and ectocuneiform was oblique, at approximately $35^{\circ}$, to the horizontal axis. However, the proximodistal orientation of Mt IV was such that its distal end was more plantar in position than its proximal end, as shown by the fused Mt IV and Mt V that occurs in some specimens (e.g., Eremotherium laurillardi, ROM 28905). Mt III was capable of limited movement so the position of its distal end varied slightly. The effect of these proximal to distal differences produced a less oblique digital array distally. In addition, the navicular facet (on the astragalar head) does not lie directly dorsal to the cuboid facet of the calcaneum, but medial and slightly dorsal to it. The navicular articulated with its major axis inclined ventromedially (or plantomedially). Therefore, the digital plane was not disposed vertically as depicted in Owen (1859), but obliquely. The inclination of the digits was not constant proximodistally along the digital array: Mt V and Mt IV rested on the substrate on their lateroplantar surface, whereas the ungual phalanx of digit III rested on its lateral surface.

The contact surface with the ground (bony sole) was constituted by the ventral (plantar) aspect of the calcaneum, lateroplantar surface of $\mathrm{Mt} \mathrm{V}$, lateroplantar surface of the distal part of Mt IV, and the reduced phalanges of the fourth and fifth digits. The lateral surface, or at least part of it, of the ungual phalanx of digit III also appears to have contacted the substrate, as discussed by Toledo et al. (2015a, b, 2016), and as indicated also by ichnological evidence (see Aramayo et al. 2015). The oblique orientation of digit III thus served to keep 
part of the large keratinous claw (possibly its tip) free of the substrate.

\section{Functional morphology of the cruroastragalar joint}

Experimental manipulation of the astragalus within the crural mortise was performed in specimens with both the astragalus and tibia-fibula preserved (e.g. M. americanum, MLP 2-30, MACN-PV 54; E. laurillardi, USNM 457115). The displacement observed was mainly in the vertical plane (or at least in a plane subparallel to the tibia-fibular diaphyseal axis - see Fig. 5). Minor mediolateral displacement was noted, involving medial displacement during plantar flexion and lateral displacement during dorsiflexion (Fig. 6). Thus, in its proper anatomical position, the odontoid process could not have functioned as a subvertical pivot imparting a rotational motion to the pes around a vertical axis; for such motion to have been possible, the odontoid process would have to have been oriented with its long axis nearly vertically.

These findings indicate that the main movement at the ankle was dorsiflexion-plantar flexion in a more or less parasagittal plane, rather than a rotational movement in the frontal plane (Fig. 5). Therefore, the main ankle movement is similar to that described as the generalized mammal condition, including humans (see Gray 1918; Polly 2007), as was also described for Santacrucian sloths (Toledo et al. 2015a, b).

Orientation of the anatomical sole As previous analyses by De Iuliis (1996) indicated, in the megatheriines studied herein, and in accordance with the oblique orientation of the digital plane at the cuboid-ectocuneiform surfaces, the anatomical sole of the pes faced medioventrally (or medioplantarly) in both Eremotherium and Megatherium; in part this is due to the decreased degree of obliquity more distally along the digital array. The only elements raised from the substrate were the navicular (beneath which the presence of a medial soft tissue plantar pad was proposed by Toledo et al. 2016), the cuboid, meso-ectocuneiform, Mt III, and the fused proximal and middle phalanges of the third digit.

\section{Discussion}

As noted in the Introduction, previous literature defined pedolaterality on a number of criteria. The degree of modification of the astragalus, characterized by the transformation of the medial ridge of the astragalar trochlea into a peg-shaped odontoid process bearing an odontoid facet, whereas the lateral ridge arches as a broad discoid facet (De Iuliis 1994; McDonald 2003, 2007, 2012; McDonald and De Iuliis 2008; Amson et al. 2016), has been advanced as an indicator of a pedolateral pes by several authors (Scott 1903-1904; Stock 1917, 1925; Hirschfeld 1985; McDonald 2003, 2007, 2012; Argot 2008). Further, the development of an odontoid-discoid condition has been related to a lateral inclination of the cruroastragalar joint axis resulting in not only a verticalization of the digital array (i.e., a highly and permanently inverted pes), but also a change in ankle movement from dorsiflexion-plantar flexion mainly in the parasagittal plane to rotation in the horizontal (or frontal) plane.

In this regard, several authors have recognized a pedolateral pes from the presence of odontoid and discoid facets, including Stock (1925), Webb (1989), and McDonald (2007, 2012). A pedolateral pes has been recognized following this criterion in Mylodontidae, Megatheriidae, and Nothrotheriidae, whereas the condition in Megalonychidae has been described as lacking the traits related to such a modification (McDonald 2007). Thus, "primitive" sloths with a more generalized astragalus show only slight pedolateralization, while "derived" sloths with pronounced odontoid and discoid facets (e.g., mylodontines and lestodontines) naturally exhibit a higher degree of pedolateralization. On this criterion and taking into account that the astragalus of extant sloths lacks an odontoid process, it
Fig. 5 Experimental movement of right cruroastragalar joint of megatheriines, showing that movement occurs mainly in the same plane as the tibia-fibula diaphyseal axis, as may be noted by the degree of deviation of the navicular facet of the astragalus between dorsiflexed and plantar flexed positions (modified from De Iuliis 1996). a, b anterior view; c, d lateral view. The astragalus is $\mathbf{a}$ and $\mathbf{c}$, in dorsiflexed position, $\mathbf{b}$ and $\mathbf{d}$, in plantar flexed position. Scale bar $=10 \mathrm{~cm}$
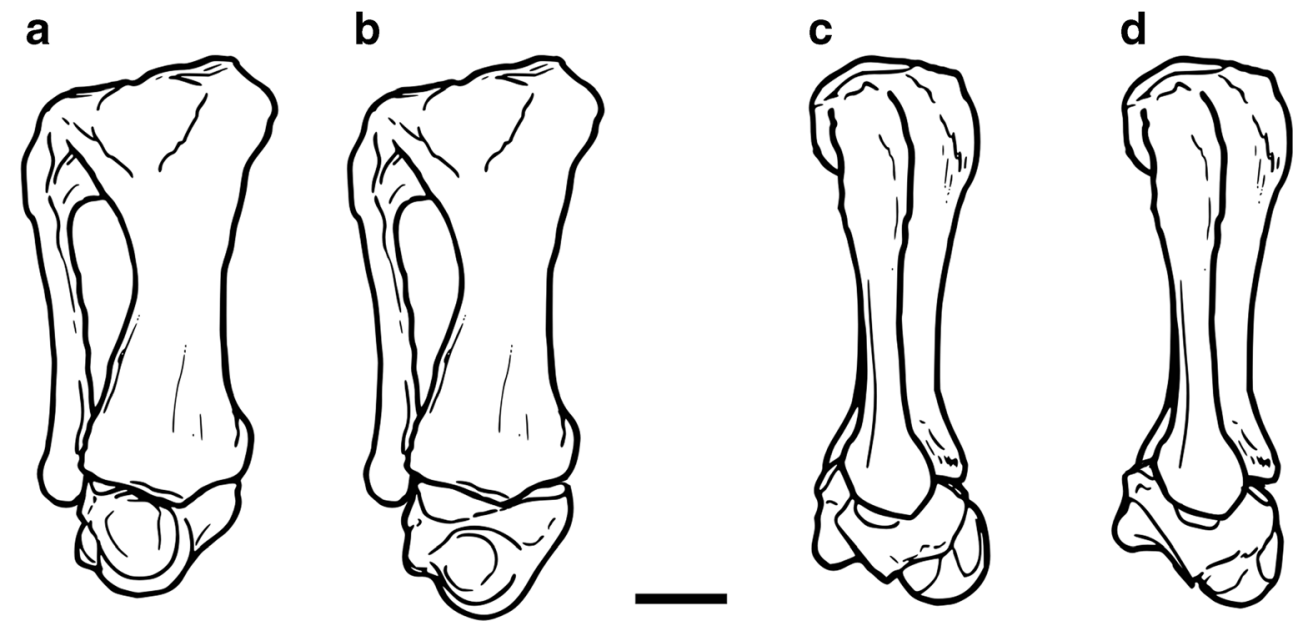
also follows that they are not pedolateral (McDonald 2007). According to Hirschfeld (1985) and McDonald (2003, 2007), "derived" astragalar features linked to a pedolateral stance are: 1- presence of an odontoid process; 2- discoid and odontoid facets approximately orthogonal to each other; 3 - discoid facet flattened posteriorly; and 4- discoid facet posteriorly extended with respect to the odontoid facet.

Variation of the pedolateral pattern, according to McDonald (2007), involves differences in the proportion of the calcaneum resting on the surface, and the angle between facets on Mt V for the cuboid and Mt IV. The cuboid served as point of transmission of weight from the calcaneum toward digit V (Hirschfeld 1985; McDonald 2007, 2012). McDonald (2012: 213) also considered that concurrent "with the increased amount of mediolateral rotation of the pes, there is an increase in the degree of curvature of the lateral margin of the astragalus," and that the "greatest amount of curvature of the lateral margin of the astragalus is seen in the megatheres."

Hirschfeld (1985) proposed that the extant anteaters Myrmecophaga and Tamandua could be used as a model of basal mammalian foot architecture and ancestral type for ground sloths. Features of the more well-represented early Miocene Santacrucian sloths (e.g., Hapalops, Analcimorphus) are congruent with Hirschfeld's hypothesis and also with the traditional depiction of a generalized mammalian pes sensu Polly (2007): a pentadactyl, plantigrade low-arched pes without significant reduction and/or fusion of elements (Scott 1903-1904; Bargo et al. 2012; Toledo et al. 2015a, b). According to Hirschfeld (1985), modifications from this generalized condition towards a derived, specialized foot pattern of Pleistocene terrestrial sloths involves:

1- loss or reduction of inner digits;

2- increase of size and robustness of outer digits (which does not occur in extant sloths);

3- dorso-medial rotation of the arch of the foot (which occurs in most, including extant, sloths) with transference of weight bearing towards the lateral surface (but not in extant sloths);

4- posterior extension of the calcaneum (as in most sloths and also in other plantigrade mammals such as humans);

5- dorsal development of the medial astragalar condyle (not applicable to extant sloths and the orientation dependent on the reconstructed position of the astragalus); and

6- an unspecified "basic reorganization of the structural relationship of various tarsal and metatarsal elements" (Hirschfeld 1985: 58).

However, the results of the analyses of the present contribution indicate that, at least for the megatheriines studied herein, there is no obvious correlation between the presence of an odontoid-discoid condition and the verticalization of the cruroastragalar joint axis and digital array (without application of marked knee abduction so pronounced that it would cause dislocation). Indeed, we have found no evidence that relates the transformation of the medial trochlea into an odontoid process and a change of the direction of movement of the pes from mainly dorsiflexion-plantar flexion into mediolateral rotation, in contrast to Hirschfeld's (1985) and McDonald's (2007 and 2012) suggestions. Moreover, the criterion for determining direction of the cruroastragalar rotation axis is the inclination of the plane between the astragalar trochlear plane and the cochlea tibiae. Findings on specimens analyzed in this work are coherent with prior unpublished analyses performed by one of us in his dissertation (De Iuliis 1996).

Therefore, and converse to the descriptions based on Owen (1859), the pes of megatheres was not fully inverted as a whole. When the femur and tibia are aligned approximately in the parasagittal plane, the position and orientation of both the astragalus and calcaneum are, in the specimens analyzed, similar to those of other mammals, as indicated also by previous literature (see McDonald 2003, 2007) and that Toledo et al. (2015a, b) recognized in early Miocene Santacrucian sloths. Only the digital plane is slightly inclined, as in early Miocene sloths and, for example, in the human pes (whereas it is orthogonal in extant sloths) and perhaps different to what Amson et al. (2016: 9) characterized as metatarsals "stacked partly dorsoventrally." Thus, Owen's depiction of a vertical digital array in Megatherium is not appropriate. The relative positions of the astragalar head and cuboidal facets of both the astragalus and calcaneum determine the inclination of the digital array. Therefore, inclination of the digital plane (and hence inversion of digits) is related more closely to the relative positions of the navicular and cuboid (and so to the relative position of the astragalar head with respect to the calcaneum, as McDonald (2003) stated that the rotation of the foot occurs) than to the degree of development of odontoid and discoid facets. As well, the idea that a strongly curved lateral margin of the astragalus, most markedly so in megatheriines, that was noted by McDonald (2012) as another indication of mediolateral rotation of the pes, requires, based on the results of this study, further scrutiny. It is worth noting that both specimens of Megatherium mounted at present in the MLP and Paris galleries reconstruct the pes in a posture corroborated by the findings presented here (Figs. 7 and 8).

Thus, it is not that factors distal to the cruroastragalar joint have been ignored in understanding the inverted pes in many terrestrial sloths, but that the extent of their role has been overshadowed in deference to the importance of astragalar morphology. This is clearly illustrated by McDonald's (2012: 209) statement that while "the rotation of the foot occurs as a functional complex resulting in the modification of 
Fig. 6 Experimental movement of left cruroastragalar joint in Eremotherium, USNM 457115, in anterior view, from dorsiflexed (left) to plantar flexed (right) positions. Black circles show relative position of the same anatomical point, dotted line describes the total displacement, and the white "L" depicts relative vertical and horizontal displacement

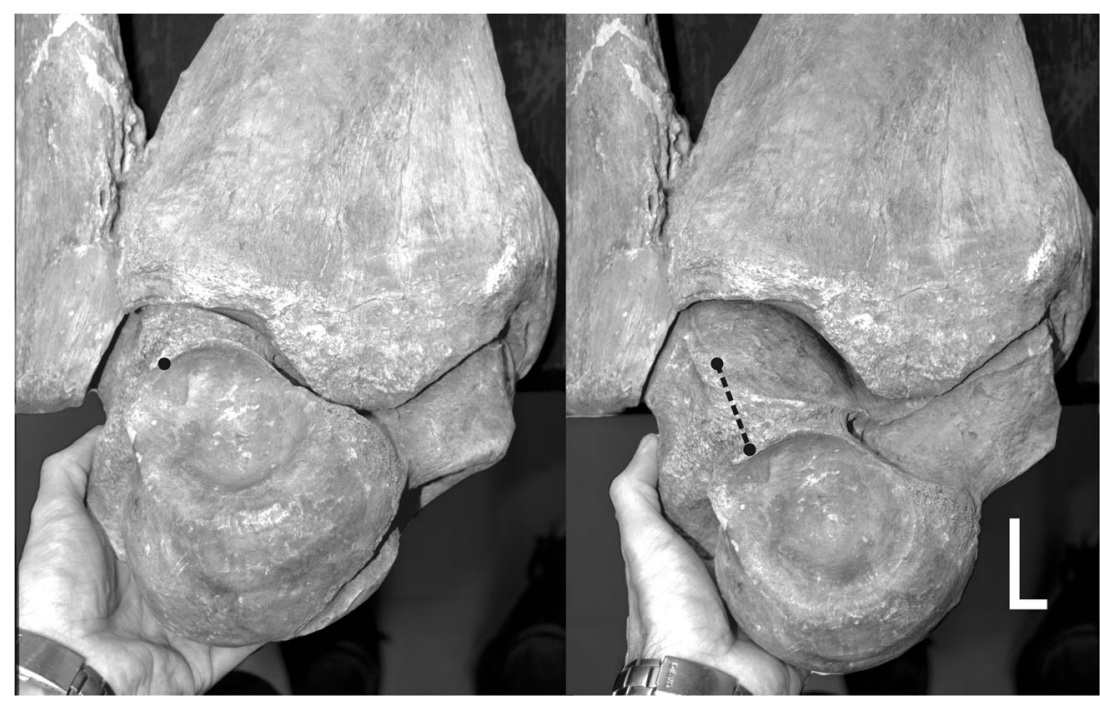

many bones in the pes, the astragalus is the one bone that shows the highest degree of departure from the primitive mammalian condition and the most distinctive changes in morphology." However, as demonstrated in this contribution (and summarized below), it would seem that the astragalus in megatheriines, despite possessing among the more notably developed odontoid and discoid facets among sloths, functions much like the astragalus in a typical plantigrade mammal, with most movement occurring in a nearly parasagittal plane. In other words, the odontoid and discoid morphology does not have much bearing on an orientation of the astragalus that is notably different than usual among mammals, and thus with producing the marked inversion that has come to be considered characteristic of many terrestrial sloths. Perhaps this should not come as a surprise: as is generally well known, inversion and eversion movements of the pes in humans are not produced mainly at the cruroastragalar joint, but primarily at the joints among the astragalus, calcaneum, and navicular, and the subtalar joints (Gray 1918; Polly 2007).

With regard to functional morphology, movement at the cruroastragalar joint occurs mostly in the parasagittal plane, producing dorsiflexion and plantar flexion. Slight rotation around the vertical axis also occurs so that the pes moves slightly medially in plantar flexion and slightly laterally in dorsiflexion. Such deviation from a strictly parasagittal plane, however, is not atypical in many mammals. For example, manipulation of the equine astragalus and tibia demonstrates such motion (albeit in the opposite direction) during dorsiflexion and plantar flexion. The combined movement described by the pes in Megatherium and Eremotherium thus involves mainly plantar extension (with slight medial excursion) and mainly dorsiflexion (with slight lateral excursion), as in other mammals (see Lewis 1980). Nevertheless, in no specimen studied here does the pes appear to have moved mainly in the horizontal plane and hence did not rotate horizontally around the odontoid process, in contrast to proposals made in previous literature (Hirschfeld 1985; McDonald 2003, 2007, 2012). In this context, changes in the actions of the pes and the digital extensor and flexor musculature (with respect to the generalized mammalian function) proposed by Hirschfeld (1985) and McDonald (2003, 2007, 2012) may require revision for megatheriines.

The characteristics of the megatheriine astragalus that depart most markedly from those of typical plantigrade mammals are the odontoid process (and its facet) and the discoid facet. As noted, these characteristics have been explained as due mainly to the development of an inverted pes and a mediolateral rotation of the pes. However, this posture and function do not seem to be adequate explanations for the form of these features, at least not in megatheriines. In some ways, these articular surfaces are so notably distinct because of the disparity in the size of the medial and lateral surfaces of the astragalar trochlea. This seems to have been caused by a reduction in the extent of the medial surface, which has thus produced the peg-shaped form of the odontoid process, rather than an increase in size of the lateral surface. The deep groove between these facets is atypical of the astragalus of the pes of most other plantigrade mammals, but is typical of many cursorial mammals such as equids and cervids (but in which the medial and lateral facets of the astragalus are nearly equal in size). The function of this morphology in such mammals is generally cited as being the enhancement of stabilization of the cruroastragalar joint to restrict movement in the parasagittal plane, thereby enhancing efficiency in rapid locomotion (see Polly 2007). Clearly, whereas speed was unlikely a concern among sloths, stabilization of the cruroastragalar joint must have been important, although this does not explain the morphology of the odontoid process (i.e., the marked disparity between the lateral and medial surfaces of the astragalar trochlea). 
Fig. 7 Dorsal (left) and lateral (right) views of left pes of a mounted specimen of Megatherium americanum at the Museo de La Plata, La Plata, Argentina (MLP 2-73). The perspective in the lateral view appears to show the digital plane as vertically oriented but compare with the dorsal view and Fig. $2 b$ for an appreciation of the position of the digits. Scale bar $=5 \mathrm{~cm}$
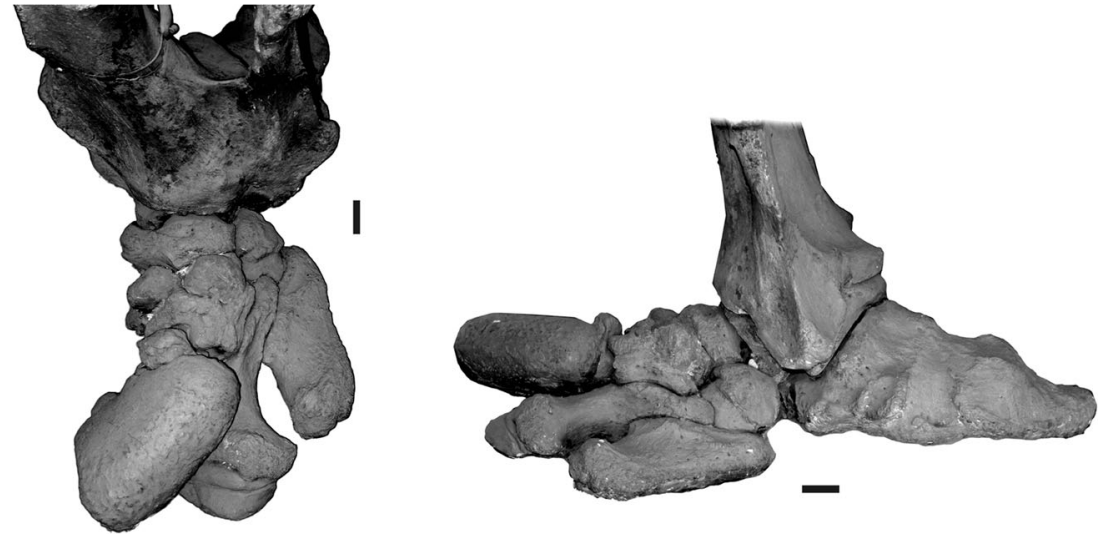

\section{Concluding Remarks}

Summarizing, the only criteria proposed by Hirschfeld (1985) for mylodontids that are exhibited in the megatheriines studied in the current analysis are:

1- loss or reduction of inner digits (also occurring in extant but not in early Miocene sloths);

2- increase in size and robustness of the lateral digits (which does not occur in extant sloths, in which digit $\mathrm{V}$ is reduced or absent and the remaining digits are more or less equally developed), and of only their metapodial segments, whereas their phalangeal elements are vestigial or absent;

3- inclination of the digital array (equivalent to Hirschfeld's 1985 "dorsomedial rotation of the arch of the pes"), shared by most, including extant, sloths, with transference of weight bearing towards the lateral side (not applicable to extant sloths).

thus, the results of the analyses conducted here suggest that the response to both questions posed in the Introduction (does the presence of a well-developed odontoid process necessarily indicate 1- full pedolaterality, and 2- that the astragalus moved -rotated- at the cruroastragalar joint, mainly or entirely mediolaterally in the horizontal or frontal plane) is no.
The traditionally accepted views of pedolaterality suggest an adaptive link between the development of an odontoid process and pedolaterality. That is, the function of having an odontoid process in its most extreme expressions is that it permits a pedolateral posture (with plantar surface facing nearly or entirely medially) and rotation of the pes in the horizontal plane. Our results suggest that such a tight causal relationship may not be warranted. We do not claim that there is no link. However, if such a causal relationship exists, it does it does not appear to be supported by the conditions described for Megatherium and Eremotherium. This, in turn, may mean that we need to reconsider the functional significance of a well-developed odontoid process.

Indeed, it is proposed here that the key anatomical criterion for defining pedolaterality in megatheriines is inclination of the digital plane, which can be inferred from the relative positions of the navicular and cuboid. It is necessary here to expand the research to include not only the more derived extinct terrestrial sloths, but also extant sloths, in which verticalization of the digital plane is verified without development of an odontoiddiscoid astragalar condition, and even anteaters. Studies in progress by the current authors will expand the survey to other taxa and lineages in order to shed light on the evolution of the pedal architecture of sloths and include muscular and ligamentous reconstruction to assess pes function.
Fig. 8 Articulated specimen of Megatherium americanum exhibited in the Muséum National d'histoire Naturelle (MNHN), Paris, France. Note the position of astragalus respect to the tibiafibula and the low inclined digital plane, similar to that exhibited by the MLP specimen of Fig. 7

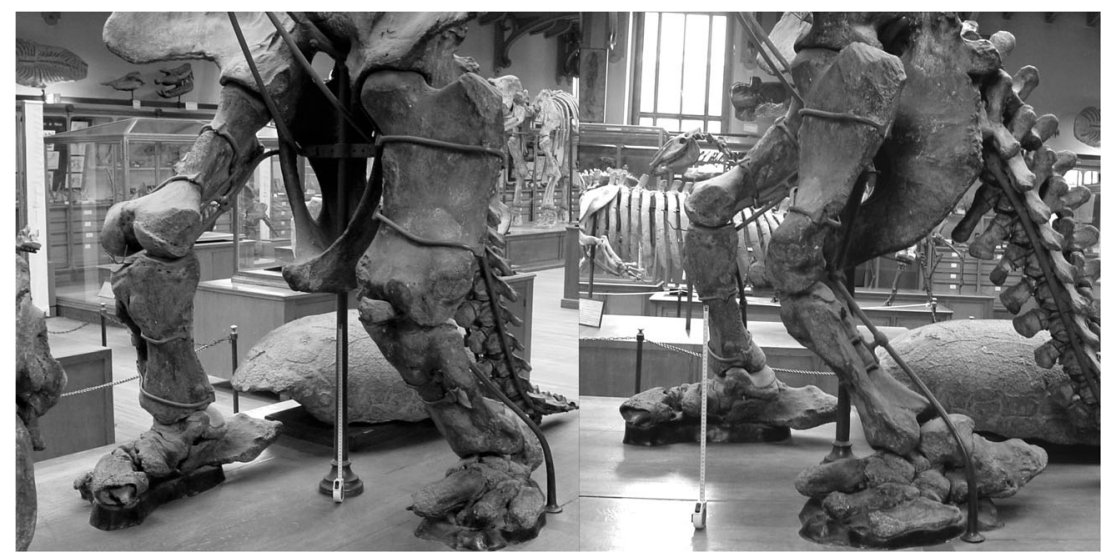


Acknowledgements The authors thank collection managers and chairs of institutions housing specimens analyzed in this work (AMNH, FMNH, USNM, MACN, MLP, ROM, YPM) for kindly granting access to materials in their care; to J. Nyakatura, J.C. Fernicola, R. Kay, G.H. Cassini, and A. Racco for providing valuable suggestions; and to Eli Amson and one anonymous reviewer for greatly improving the quality of this work. This contribution was presented during the ICVM 11 meeting in Bethesda (Washington, D.C.) in July 2016, as part of the symposium Morphology and Evolution of the Xenarthra organized by M. Susana Bargo and John A. Nyakatura. Attendance at the congress was partially granted by UNLP Viajes y Estadías 2016 to SFV and NT, and CIC 1827/15 (Comisión de Investigaciones Científicas de la provincia de Buenos Aires) to MSB. This is a contribution to the projects UNLP 11/N750 (Universidad Nacional de La Plata) and PICT 2013-0386 and 0389 (Agencia Nacional de Promoción Científica y Técnica). Data sharing is not applicable to this article as no datasets were generated or analyzed during the current study.

\section{Compliance with ethical standards}

Conflicts of interest None

\section{References}

Amson E, Argot C, McDonald HG, Muizon C de (2015a) Osteology and functional morphology of the hind limb of the marine sloth Thalassocnus (Mammalia, Tardigrada). J Mammal Evol 22:355419. https://doi.org/10.1007/s10914-014-9274-5

Amson E, Argot C, McDonald HG, Muizon C de (2015b) Osteology and functional morphology of the axial postcranium of the marine sloth Thalassocnus (Mammalia, Tardigrada) with paleobiological implications. J Mammal Evol 22: 473-518

Amson E, Muizon C de, Gaudin TJ (2016) A reappraisal of the phylogeny of the Megatheria (Mammalia: Tardigrada), with an emphasis on the relationships of the Thalassocninae, the marine sloths. Zool J Linn Soc. https://doi.org/10.1111/zoj.12450

Amson E, Muizon C de, Laurin M, Argot C, de Buffrénil V (2014) Gradual adaptation of bone structure to aquatic lifestyle in extinct sloths from Peru. Proc Roy Soc B-Biol Sci 281(1782): 1-6

Amson E, Nyakatura JA (2017) The postcranial musculoskeletal system of xenarthrans: insights from over two centuries of research and future directions. J Mammal Evol. https://doi.org/10.1007/s10914017-9408-7

Aramayo SA, Manera de Bianco T, Bastianelli NV, Melchor RN (2015) Pehuen Co: updated taxonomic review of a late Pleistocene ichnological site in Argentina. Palaeogeogr Palaeoclimatol Palaeoecol 439: 144-165

Argot C (2002) Functional-adaptive anatomy of the hindlimb in the Didelphidae, and the paleobiology of the Paleocene marsupials Mayulestes ferox and Pucadelphys andinus. J Morphol 253: 76-108

Argot C (2008) Changing views in paleontology: the story of a giant (Megatherium, Xenarthra). In: Sargis EJ, Dagosto M (eds) Mammalian Evolutionary Morphology: A Tribute to Frederick S. Szalay. Springer Science, Dordrecht, pp 37-50

Bargo MS, Toledo N, Vizcaíno SF (2012) Paleobiology of the Santacrucian sloths and anteaters (Xenarthra, Pilosa). In: Vizcaíno SF, Kay RF, Bargo MS (eds) Early Miocene Paleobiology in Patagonia: High-latitude Paleocommunities of the Santa Cruz Formation. Cambridge University Press, Cambridge, pp 216-242

Bargo MS, Vizcaíno SF, Archuby FM, Blanco RE (2000) Limb bones proportions, strength and digging in some Lujanian (late Pleistocene-early Holocene) mylodontid ground sloths (Mammalia. Xenarthra). J Vertebr Paleontol 20: 601-610
Blanco RE, Czerwonogora A (2003) The gait of Megatherium Cuvier 1796 (Mammalia, Xenarthra, Megatheriidae). Senckenberg Biol 83: $61-68$

Brandoni D (2006) A review of Pliomegatherium Kraglievich 1930 (Xenarthra: Phyllophaga: Megatheriidae). N Jb Geol Paläontol Mh 4: 2012-2224

Brandoni D, Carlini AA, Pujos F, Scillato-Yané GJ (2004) The pes of Pyramiodontherium bergi (Xenarthra, Tardigrada): the most complete pes of a Tertiary Megatheriinae. Geodiversitas 26: 643-659

Candela AM, Picasso MBJ (2008) Functional anatomy of the limbs of Erethizontidae (Rodentia, Caviomorpha): indicators of locomotor behavior in Miocene porcupines J Morphol 269: 552-593

Casinos A (1996) Bipedalism and quadrupedalism in Megatherium: an attempt at biomechanical reconstruction. Lethaia 29: 87-96

Chiarello AG (2008) Sloth ecology: an overview of field studies. In: Vizcaíno SF, Loughry WJ (eds) The Biology of the Xenarthra. University Press of Florida, Gainesville, pp 269-280

De Esteban-Trivigno S, Mendoza M, De Renzi M (2008) Body mass estimation in Xenarthra: a predictive equation suitable for all quadrupedal terrestrial placentals? J Morphol 269: 1276-1293

De Iuliis G (1994) Relationships of the Megatheriinae, Nothrotheriinae, and Planopsinae: some skeletal characteristics and their importance for phylogeny. J Vertebr Paleontol 14: 577-591

De Iuliis G (1996) A systematic review of the Megatheriinae (Mammalia: Xenarthra: Megatheriidae). Ph.D. dissertation, University of Toronto, Toronto, $756 \mathrm{pp}$

De Iuliis G, Brandoni D, Scillato-Yané GJ (2008) New remains of Megathericulus patagonicus Ameghino, 1904 (Xenarthra, Megatheriidae): information on primitive features of megatheriines. J Vertebr Paleontol 28(1): 181-196

De Iuliis G, Pulera D (2010) The Dissection of Vertebrates: A Laboratory Manual. 2nd ed. Academic Press, Amsterdam, 332 pp

de Toledo PM (1996) Locomotor patterns within Pleistocene sloths. Unpublished Ph.D Dissertation. University of Colorado, Boulder, $316 \mathrm{pp}$

Fariña RA, Vizcaíno SF, Bargo MS (1998) Body mass estimation in Lujanian (late Pleistocene-early Holocene of South America) mammal megafauna. Mastozool Neotropical 51:87-108

Gaudin TJ (1995) The ear region of edentates and the phylogeny of the Tardigrada (Mammalia, Xenarthra). J Vertebr Paleontol 15: 672-705

Gaudin TJ (2004) Phylogenetic relationships among sloths (Mammalia, Xenarthra, Tardigrada): the craniodental evidence. Zool J Linn Soc 140: 255-305

Gazin CL (1957) Exploration of the remains of giant ground sloths in Panama. Smithsonian Annu Report 1956: 341-354

Gray H (1918) Anatomy of the Human Body. Bartebly, Philadelphia

Hirschfeld SE (1985) Ground sloths from the Friasian La Venta fauna, with additions to the Pre-Friasian Coyaima fauna of Colombia, South America. Univ Calif Publ Geol Sci 128: 1-91

Jenkins FA Jr (1971) Limb posture and locomotion in the Virginia opossum (Didelphis marsupialis) and in other non-cursorial mammals. J Zool Lond 165: 303-3015

Kraglievich L (1928) Apuntes para la geología y paleontología de la República Oriental del Uruguay. Revista de la Sociedad Amigos de la Arqueología 2: 197-203

Lessertisseur J, Saban R (1971) Squelette apendiculaire. In: Grassé PP (ed) Traitè de Zoologie, Tome XVI, 3rd Fasc. Mason et Cie, Paris, pp 709-1078

Lewis OJ (1980) The joints of the evolving foot. Part I. The ankle joint. J Anat 130 (3): 527-543

Lovejoy CO (2007) The natural history of human gait and posture Part 3. The knee. Gait \& Posture 25: 325-341

McDonald HG (1977) Description of the osteology of the extinct gravigrade edentate, megalonyx, with observations on its ontogeny, phylogeny and functional anatomy. M.S. Thesis, Department of Zoology University of Florida, Gainesville, 328 pp 
McDonald HG (2003) Xenarthran skeletal anatomy: primitive or derived? (Mammalia, Xenarthra). Senckenberg biol 83: 5-17

McDonald HG (2007) Biomechanical inferences of locomotion in ground sloths: integrating morphological and track data. In: Lucas SG, Spielmann JA, MG Lockley (eds) Cenozoic Vertebrate Tracks and Traces. New Mexico Museum of Natural History and Science Bulletin 42: 201-208

McDonald HG (2012) Evolution of the pedolateral foot in ground sloths: patterns of change in the astragalus. J Mammal Evol 19:209-215

McDonald HG, De Iuliis G (2008) Fossil history of sloths. In: Vizcaíno SF, Loughry WJ (eds) The Biology of the Xenarthra. University Press of Florida, Gainesville, pp 24-36

Mendel FC (1985) Adaptations for suspensory behavior in the limbs of two-toed sloths. In: Montgomery GG (ed) The Ecology and Evolution of Armadillos, Sloths and Vermilinguas. Smithsonian Institution Press, Washington, D.C., pp 151-162

Milne N, Toledo N, Vizcaíno SF (2012) Allometric and group differences in the xenarthran femur. J Mammal Evol 19: 199-208

Muizon C de, McDonald HG, Salas R, Urbina M (2004) The youngest species of the aquatic sloth Thalassocnus and a reassessment of the relationships of the nothrothere sloths (Mammalia, Xenarthra). J Vertebr Paleontol 24: 387-397

Nyakatura JA, Petrovitch A, Fischer MS (2010) Limb kinematics of the two-toed sloth (Choloepus didactylus, Xenarthra) and its implications for the evolution of the sloth locomotor apparatus. Zoology 113: $221-234$

Owen R (1842) Description of the Skeleton of an Extinct Gigantic Sloth, Mylodon robustus Owen, with Observations on the Osteology, Natural Affinities, and Probable Habits of the Megatherioid Quadrupeds in General. R \& J Taylor, London, $176 \mathrm{pp}$

Owen R (1859) On the Megatherium (Megatherium americanum, Cuvier and Blumenbach). Part V. Bones of the posterior extremities. Phil Trans Roy Soc Lond B 149: 809-829

Patterson B, Pascual R (1968) The fossil mammal fauna of South America. Q Rev Biol 43(4): 409-451

Paula Couto C de (1978) Mamíferos fósseis do Pleistoceno do Espírito Santo. An Acad Bras Cienc 50: 365-379

Polly PD (2007) Limbs in mammalian evolution. In: Hall BK (ed) Fins into Limbs: Evolution, Development, and Transformation. University of Chicago Press, Chicago, pp 245-268

Pujos F, Gaudin TJ, De Iuliis G, Cartelle C (2012) Recent advances on variability, morpho-functional adaptations, dental terminology, and evolution of sloths. J Mammal Evol 19: 159-169

Reid F (1997) A Field Guide to the Mammals of Central America and Southeast Mexico. Oxford University Press, Oxford, 398 pp

Scott WB (1903-1904) Mammalia of the Santa Cruz beds. I. Edentata. In: Scott WB (ed) Reports of the Princeton University Expeditions to
Patagonia 1896-1899. Princeton University Press, Princeton, pp 1364

Stock C (1917) Structure of the pes in Mylodon harlani. Univ Calif Publ 10 (16): 267-286

Stock C (1925) Cenozoic gravigrade edentates of western North America with special reference to the Pleistocene Megalonychinae and Mylodontidae of Rancho La Brea. Carnegie Inst Wash 331:1-206

Toledo N (2016) Paleobiological integration of Santacrucian sloths (early Miocene of Patagonia). Ameghiniana 53:100-141

Toledo N, Bargo MS, Vizcaíno SF (2015a) Muscular reconstruction and functional morphology of the hind limb of Santacrucian (early Miocene) sloths (Xenarthra, Folivora) of Patagonia. Anat Rec 298: $842-864$

Toledo N, Cassini GH, Vizcaíno SF, Bargo MS (2014) Mass estimation of Santacrucian sloths from the early Miocene Santa Cruz Formation of Patagonia, Argentina. Acta Palaeontol Pol 59:267-280

Toledo N, Racco A, Bargo MS, Vizcaíno SF, Fernicola JC (2015b) Pedolateralización, apoyo del pie y soporte del peso corporal en perezosos fósiles (Xenarthra, Folivora). Reunión de Comunicaciones de la Asociación Paleontológica Argentina. Mar del Plata, Buenos Aires, Actas: 26

Toledo N, Racco A, Bargo MS, Vizcaíno SF, Fernicola JC (2016) Pedolateralization, foot anatomy, and weight support in extinct sloths (Xenarthra, Folivora). 11th International Congress of Vertebrate Morphology. Washington, USA, Meeting Abstracts: 208

Vizcaíno SF, Zárate M., Bargo MS, Dondas A (2001) Pleistocene burrows in the Mar del Plata area (Buenos Aires Province, Argentina) and their probable builders. Acta Palaeontol Pol 46:157-169

Webb SD (1985) The interrelationships of tree sloths and ground sloths. In: Montgomery GG (ed) The Evolution and Ecology of Armadillos, Sloths, and Vermilinguas. Smithsonian Institution Press, Washington, D.C., pp 105-112

Webb SD (1989) Osteology and relationships of Thinobadistes segnis, the first mylodont sloth in North America. In: Redford KH, Eisenberg JF (eds) Advances in Neotropical Mammalogy. The Sandhill Crane Press, Inc., Gainesville, pp 469-532

White JL (1993) Indicators of locomotor habits in xenarthrans: evidence for locomotor heterogeneity among fossil sloths. J Vertebr Paleontol 13:230-242

White JL (1997) Locomotor adaptations in Miocene xenarthrans. In: Kay RF, Madden RH, Cifelli RL, Flynn JJ (eds) Vertebrate Paleontology in the Neotropics. The Miocene Fauna of La Venta, Colombia. Smithsonian Institution Press, Washington, D.C., pp 246-264

Zarate MA, Bargo MS, Vizcaíno SF, Dondas A, Scaglia O (1998) Estructuras biogénicas en el Cenozoico tardío de Mar del Plata (Argentina) atribuibles a grandes mamíferos. Asociación Argentina de Sedimentología Revista 5 (2): 95-103 